\title{
Mental health planning at a very early stage of the COVID-19 crisis: a systematic review of online international strategies and recommendations
}

\author{
Nerea Almeda ${ }^{1 *}$ (D), Carlos García-Alonso ${ }^{2}$ (D) and Luis Salvador-Carulla ${ }^{3}$ (D)
}

\begin{abstract}
Background: Mental health care systems have been dramatically affected by COVID-19. Containment measures have been imposed, with negative consequences on population mental health. Therefore, an increase in both symptomatology and mental disorder incidence is expected. This research aims to identify, describe and assess the empirical background on online strategies and recommendations developed by international organizations and governments to cope with the psychological impact of COVID-19 at a very early stage of the pandemic.

Methods: The PRISMA guidelines were adapted to review online documents. A new questionnaire was developed to identify the existence of common patterns in the selected documents. Questions were classified into three domains: COVID-19 information, mental health strategies and mental health recommendations. A two-step cluster analysis was carried out to highlight underlying behaviours in the data (patterns). The results are shown as spider graphs (pattern profiles) and conceptual maps (multidimensional links between questions).

Results: Twenty-six documents were included in the review. The questionnaire analysed document complexity and identified their common key mental health characteristics (i.e., does the respondent have the tools for dealing with stress, depression and anxiety?). Cluster analysis highlighted patterns from the questionnaire domains. Strong relationships between questions were identified, such as psychological tips for maintaining good mental health and coping with COVID-19 (question $n^{\circ} 4$ ), describing some psychological skills to help people cope with anxiety and worry about COVID-19 (question $n^{\circ} 6$ ) and promoting social connection at home (question $n^{\circ} 8$ ).

Conclusions: When fast results are needed to develop health strategies and policies, rapid reviews associated with statistical and graphical methods are essential. The results obtained from the proposed analytical procedure can be relevant to a) classify documents according to their complexity in structuring the information provided on how to cope with the psychological impact of COVID-19, b) develop new documents according to specific objectives matching population needs, c) improve document design to face unforeseen events, and d) adapt new documents to local situations. In this framework, the relevance of adapting e-mental health procedures to community mental health care model principles was highlighted, although some problems related to the digital gap must be considered.
\end{abstract}

Keywords: COVID-19, Strategies, Recommendations, Mental health, Systematic review

\footnotetext{
* Correspondence: nmalmeda@uloyola.es

'Department of Psychology, Universidad Loyola Andalucía, Seville, Spain

Full list of author information is available at the end of the article
} 


\section{Background}

The COVID-19 outbreak has created an unprecedented crisis in modern health care systems [1]. This disease originated in Wuhan (Hubei Province, China) at the end of 2019 [2]. On January 30th, 2020, the World Health Organization [3] (WHO) declared a public and international health emergency.

On May 1st, 2020, there were 3,318,428 confirmed cases and 234,250 deaths worldwide [4]. The incidence and mortality rate of COVID-19 have saturated health systems in a number of countries. To a greater or lesser extent, containment measures such as social distancing, quarantine and self-isolation have been imposed worldwide [5]. Containment measures can have negative impacts on population mental health $(\mathrm{MH})$ [6]. People may be affected during and after containment by the precipitation of new symptoms or aggravation of previous conditions [7-10]. Considering the vulnerability of $\mathrm{MH}$ users, decision makers should also prevent a potential increase in inequalities because $\mathrm{MH}$ users experience more distress, fear, anxiety and depression than the general population [11], which can worsen their previous circumstances [12].

Female gender, being a student and poor health status are factors that have been associated with greater psychological impact [13]. Li, Wang, Xue, Zhao and Zhu [14] found that after the COVID-19 outbreak, negative emotions increased, while happiness and life satisfaction decreased. Patients with COVID-19 manifest posttraumatic stress symptoms before and after discharge [15, 16]. People in quarantine and COVID-19 patients feel fear, boredom, anger, loneliness and/or stress [17] and may suffer from hate crimes, fear, alienation and discrimination [18]. People who have lost their loved ones are prone to developing $\mathrm{MH}$ complications related to grief after their unexpected loss and social isolation [19].

Professionals who care for COVID-19 patients are highly susceptible to psychological burden [20]. The fear of becoming infected, the suffering of patients and relatives, shortages of medical and protection supplies, and socioeconomic uncertainty increase their psychological impact $[21,22]$. Therefore, it is crucial to support these professionals by designing specific $\mathrm{MH}$ interventions [23], such as developing screenings to detect depression and anxiety [17] and to assess the psychological condition of COVID-19 patients [7].

In this new environment, it is likely that the balanced $\mathrm{MH}$ care model [24] must be adapted to consider the problem of dealing with the community-based care paradigm in a situation where a safe distance between people may be mandatory. For inpatient care, the scientific literature recommends screening users for COVID-19 symptomatology before and during hospitalization to reduce visits and to reduce the size of psychotherapy groups to minimize nonessential contacts [25]. Patients should be isolated in rooms and the length of stay should be reduced to minimize hospital-acquired infection risks [26]. Regarding community treatment services (partial hospitalization, intensive outpatient care, day care and medication services), telepsychiatry is highly recommended to limit contact, except in cases of lifethreatening emergencies [26].

The Italian Society of Epidemiological Psychiatry [27] described a proposal for $\mathrm{MH}$ care provision during the pandemic: 1) outpatient care should be mainly provided remotely, by telephone or videoconference; 2) in case of crisis, users could access acute $\mathrm{MH}$ care in hospitals; 3) day care services will be closed during the pandemic, but necessary online interventions such as telephone monitoring and face-to-face home visits should be available; 4) patients in clinical emergencies will be admitted to inpatient units, although the length of stay should be kept to a minimum and, whenever possible, the crisis should be treated outside of the hospital; and 5) short- and long-term residential care facilities will provide care normally but without admitting new patients, except as an alternative to inpatient care. Special prevention measures, such as training in the use of personal protection equipment, must be available at any time or place.

The Australian government has developed a set of digital resources based on phone and online support services, including counselling, digital peer support and emergency lines [28], in addition to the Better Access Pandemic Support resource for providing MH care [29]. Users have access to psychiatrists, psychologists and general practitioners; receive 10 initial individual sessions and, when needed, can receive 10 additional sessions.

In Canada, the Centre for Addiction and Mental Health [30] has developed a long-term system-wide response, including $\mathrm{MH}$ resources, care, new models of $\mathrm{MH}$ care provision, workplace $\mathrm{MH}$, investment in social determinants of health and a public health approximation for alcohol policy. This strategy highlights the virtual $\mathrm{MH}$ care provision trying to guarantee continuity of care and meet user needs (including information) while maintaining physical distancing.

The United States has developed a specific set of recommendations for each main type of care [31]: (a) virtual and telephone-based $\mathrm{MH}$ for outpatient care, (b) screening tests for partial hospital programmes, (c) screening protocols, triage for risk exposure, rapid tests before admission and physical distancing in emergency psychiatric care, (d) special inpatient care units for people infected with COVID-19, (e) virtual care for consultation liaison services and staff protection with PPE if virtual care is not possible, and finally, (f) secure response protocols for shelter homes and mobile care at home for community care services. 
The Royal College of Nursing and the Royal College of Psychiatrists in the United Kingdom have developed COVID-19 guidance on mental health care delivery [32]. In this framework, an inpatient care routine review is recommended to avoid close contact activities and reduce their duration, maintaining attendance quality [33]. In psychiatric intensive care, it is recommended to balance benefits and risks prior to patient admission, provide information about the risks, carry out control measures and isolate patients in case of infection, among other actions [34]. Regarding outpatient care, it is crucial to provide continuity of care (including specific interventions to reduce crises), ensure medication continuity and keep patients and families informed [35]. Finally, for residential care facilities and supported living services, safe working measures are required by developing isolation precautions and increasing the utilization of telepsychiatry [35].

Face-to-face interventions have to be restructured in this pandemic [7]. e-MH should be reinforced [36] because it increases accessibility and equity but only when MH staff are specifically trained $[37,38]$. In this framework, telepsychiatry has achieved a relevant role in providing $\mathrm{MH}$ care, especially in prevention, psychoeducation, counselling, treatment and emergency interventions [39]. However, this model shows some drawbacks, especially for older adults who lack digital skills [40] and people with cognitive impairments.

On the other hand, general prevention strategies should be based on family support, education and selfcare, where interdisciplinary agencies (health, housing, employment and education) should collaborate to identify risk factors and promote help-seeking [41].

Several international organizations have published many recommendations and tips to cope with this health crisis. The WHO proposed to guide people in psychosocial aspects related to COVID-19, ensure referral pathways among sectors, provide $\mathrm{MH}$ and psychosocial support for all people, and meet population needs in people with pre-existing conditions, older adults, etc. [42]. In addition, the WHO is concerned with avoiding stigma and addressing bereavement and other psychological consequences. The American Psychological Association (APA) [43] provides a wide range of resources for e- $\mathrm{MH}$ and telepsychology. It shares scientific findings that can help people cope with the emotional impact of the pandemic. For the general population, specific strategies have been proposed for reducing stress, anxiety and grief, including measures for those collectives triggered by domestic violence and child abuse. The APA advises seeking help when needed, so it is necessary to improve accessibility to $\mathrm{MH}$ services. Staying healthy at home is essential for the United Nations (UN) [44], especially for those suffering from anxiety or stress. The
UN's MH strategy proposes good practices for teleworking, wellbeing management and talking with children; highlighting the roles of telepsychiatry and telecounselling. The $\mathrm{UN}$ is concerned with the existence of reliable information sources on how to access $\mathrm{MH}$ services and obtain medication. Globally, strategies to mitigate the pandemic impact focus on promoting engagement with $\mathrm{MH}$ users, clinicians and state policies [45].

This research aims to identify, describe and assess the empirical background on online strategies and recommendations developed by international organizations and governments to cope with the psychological impact of COVID-19 at a very early stage of the pandemic. Potential common patterns (links between questions) among selected documents will be identified and described.

\section{Methods}

This section has been divided into the following analytical processes: a) methods for study selection (two items: search strategy and eligibility criteria and study selection), b) questionnaire design, c) variable grouping, d) data collection procedure and, finally, e) cluster analysis of the indicator groups.

\section{Search strategy and eligibility criteria}

In this paper, a strategy is a set of general orientations to guide the design and development of specific policies. A recommendation is a specific action-clinical or organizational-implemented by decision makers to change the situation of any system (in this case, an $\mathrm{MH}$ system).

Due to the urgent character of current policy-making, an adaptation of the PRISMA guidelines [46] was developed to carry out the systematic review. The search strategy was based on the PICOS research question where the population (P) was $\mathrm{MH}$ services and systems ("mental health service" ${ }^{* "}$ OR "mental health system" "). The intervention (I) was any international online $\mathrm{MH}$ strategy or recommendation developed to address the COVID-19 psychological impact ("strateg" OR "recommendation" AND "Covid-19" OR "2019-nCOV" OR "SARS-COV-2"). The comparator (C) was not applicable. The outcomes $(\mathrm{O})$ were any online international report or guide that included any $\mathrm{MH}$ and/or psychosocial considerations for the virus ("report" OR "document* OR "guideline*). Finally, setting (S) referred to the countries included in the review. Although the PRISMA guidelines were initially designed for reviewing research articles where their $(\mathrm{P})$ was "patients", previous work has shown that the methodology is also appropriate for reviewing studies whose population or unit of study are $\mathrm{MH}$ services or systems [47-49].

The initial search strategy was "COVID" + "mental health". This retrieved a huge number of records 
(millions) that could not be managed. For this reason, new constraints were added to the initial search strategy. After checking different key word combinations, the final search strategy comprised the main terms (translated to the corresponding languages): "mental health service" " OR "mental health system" AND "strateg* OR "recommendation" AND "COVID-19" AND "report" OR "document" OR "guideline". This search strategy and the corresponding inclusion criteria were checked by two panels of experts (including psychiatrists, psychologists, managers and policy makers), one from the International CIty and urban Regional CoLlaborativE (I-CIRCLE) group and the other from the PSICOST research group.

The search strategy was piloted in Google on April 15th, 2020. To keep Google variability under control, two authors (NA and CGA) piloted the search strategy in different computers and places (geographical areas). The Google platform was selected because it provides access to government, institution, association and mass media webpages where target strategies and recommendations, which are not included in the standard indexed databases, are published.

The inclusion criteria were online $\mathrm{MH}$ reports or guides published by governments, associations, institutions and relevant media at any time to address the psychological impact of COVID-19. The languages included were English, Spanish, French, Italian and Portuguese. Countries included in the review were those that had developed strategies and recommendations before 15 April 2020 and were accessible from Google. These countries were Australia, Canada, China, England, Finland, Germany, Switzerland and France, Greece, Ireland, Italy, Mexico, New Zealand, Portugal, Spain, Scotland and the United States of America.

The reasons for exclusion were as follows: a) documents not focused on general $\mathrm{MH}, \mathrm{b}$ ) lacking information about online $\mathrm{MH}$ care provision, c) including strategies for workers and d) studying the pandemic economic impact.

\section{Study selection}

CGA and NA performed the selection process in the eligibility phase by reading the document full text, including their links. The concordance rate between authors was analysed using Kappa and two-way random ICC tests. Selected documents were characterized by including general data and identifying symptomatology and mental disorders. The characteristics of the selected document content were statistically analysed.

\section{Checklist for assessing guides}

A new questionnaire for assessing the content of the selected document was designed to identify common patterns (key subjects for decision makers and their links).
Questions were selected following the guidelines from the WHO, APA, UN, Centers for Disease Control and Prevention and, finally, MH Europe. The items (39) were initially identified by the authors and a panel of experts from the PSICOST scientific group (Table 1) and organized into three domains: 1) COVID-19 general information, 2) $\mathrm{MH}$ strategies and 3) $\mathrm{MH}$ recommendations. Domains 2 and 3 distinguished 1) MH topics, e.g., psychological tips and anxiety, from 2) MH-related topics, e.g., people with disabilities and healthcare workers.

\section{Indicator groups (variable sets)}

The questionnaire items (Table 1) were classified into seven indicator groups (IG) or variable sets.

1) Mental symptoms (IG1). Independent variables: loneliness, sleeping problems, bereavement and depression. Non-independent variable (see cluster analysis in this section): anxiety. Nondiscriminatory variable: stress. A non-discriminatory variable has the same value (YES) in all documents and therefore does not provide any information.

2) Mental disorders (IG2). Independent variables: schizophrenia, bipolar, depression, substance use disorder, eating disorder and obsessive-compulsive disorder. Non-independent variables: anxiety, chronic pain and dermatillomania.

3) COVID-19 information (IG3). Independent variable: Question 1 (Q1). Non-independent variables: Q2 and Q3.

4) $\mathrm{MH}$ strategies and $\mathrm{MH}$ topics (IG4). Independent variables: Q29, Q26, Q27 and Q39. Nonindependent variables: $Q 28$ and Q32. Nondiscriminatory variables: $Q 4, Q 6$ and $Q 8$.

5) $\mathrm{MH}$ strategies and $\mathrm{MH}$-related topics (IG5). Independent: Q5, Q25, Q30, Q34 and Q35. Nonindependent: Q31, Q33, Q36, Q37 and Q38.

6) $\mathrm{MH}$ recommendations and $\mathrm{MH}$ topics (IG6). Independent: Q9, Q10, Q11 and Q14. Nonindependent: Q12, Q13, Q15, Q16, Q17 and Q21. Non-discriminatory: $Q 7$.

7) $\mathrm{MH}$ recommendations and $\mathrm{MH}$-related topics (IG7). Independent: Q19, Q22, Q23 and Q24. NonIndependent: Q20.

\section{Data collection}

According to the structure of the questionnaire, CGA and NA independently extracted data (values for the variables, mostly binary 1: YES, the item has been found and $0: \mathrm{NO}$, the item is not included in the document) from the included studies. If discrepancies between authors were found, LSC made the final decision. The information extracted was related to the country of publication, type of document, symptomatology, mental 
Table 1 Checklist for assessing the selected guides

\begin{tabular}{|c|c|c|c|}
\hline Item & Question: Does the document ... (answer: Yes or No) & $\begin{array}{l}\text { Cod } \\
1^{\mathrm{a}}\end{array}$ & $\begin{array}{l}\text { Cod } \\
2^{\mathrm{b}}\end{array}$ \\
\hline 1 & ... include information related to the latest information on COVID-19? & 1 & \\
\hline 2 & ... include information on the strategies designed by the government in response to the pandemic ...)? & 1 & \\
\hline 3 & ... include information on the latest news about the global response to the COVID-19 outbreak? & 1 & \\
\hline 4 & ... include psychological tips for maintaining good MH and coping with COVID-19? & 2 & 1 \\
\hline 6 & ... describe some psychological skills to help people cope with anxiety and worry about COVID-19? & 2 & 1 \\
\hline 8 & ... promote social connection at home? & 2 & 1 \\
\hline 26 & ... include information on how to support a loved one who is very anxious about COVID-19? & 2 & 1 \\
\hline 27 & ... include information on how to manage stress while people await test results? & 2 & 1 \\
\hline 28 & ... include information on how to manage stress if people test positive? & 2 & 1 \\
\hline 29 & ... include information on stigma and how to reduce it? & 2 & 1 \\
\hline 32 & ... include information on how to manage stress and anxiety? & 2 & 1 \\
\hline 39 & ... include links for older adults related to any symptoms or mental disorders? & 2 & 1 \\
\hline 5 & ... include information on how to maintain a healthy lifestyle? & 2 & 2 \\
\hline 25 & ... include special mention of people with disabilities? & 2 & 2 \\
\hline 30 & ... include information for healthcare workers? & 2 & 2 \\
\hline 31 & ... include information on how to support health care workers? & 2 & 2 \\
\hline 33 & ... develop a strategy for identifying healthcare staff needs as a result of the coronavirus pandemic? & 2 & 2 \\
\hline 34 & ... include information for domestic violence victims? & 2 & 2 \\
\hline 35 & ... include information for caregivers? & 2 & 2 \\
\hline 36 & ... include information on financial support for businesses/people affected by COVID-19? & 2 & 2 \\
\hline 37 & ... provide advice on medication access during the COVID-19 pandemic? & 2 & 2 \\
\hline 38 & ... consider working at home? & 2 & 2 \\
\hline 7 & ... provide emotional support, such as conversations for sharing tips online? & 3 & 1 \\
\hline 9 & ... describe how to access MH services? & 3 & 1 \\
\hline 10 & ... provide phone or online $\mathrm{MH}$ services? & 3 & 1 \\
\hline 11 & ... offer an online psychological assessment? & 3 & 1 \\
\hline 12 & ... provide feedback on the psychological assessment results? & 3 & 1 \\
\hline 13 & ... provide $\mathrm{MH}$ treatment/intervention alternatives? & 3 & 1 \\
\hline 14 & ... provide telephone or online contact with the general practitioner? & 3 & 1 \\
\hline 15 & ... provide telephone or online contact with the psychologist? & 3 & 1 \\
\hline 16 & ... provide telephone or online contact with another $\mathrm{MH}$ professional? & 3 & 1 \\
\hline 17 & ... provide an online community forum? & 3 & 1 \\
\hline 18 & ... provide suicide and crisis support? & 3 & 1 \\
\hline 21 & ... provide steps for understanding children's feelings? & 3 & 1 \\
\hline 19 & ... include information for parents? & 3 & 2 \\
\hline 20 & ... include information on how to explain the coronavirus to children? & 3 & 2 \\
\hline 22 & ... provide alternatives to older adults to stay connected online? & 3 & 2 \\
\hline 23 & ... help in establishing online and learning digital literacy skills? & 3 & 2 \\
\hline 24 & $\begin{array}{l}\text {... include guidelines for COVID-19 outbreaks in residential care facilities (for people with physical and MH disabilities, other } \\
\text { community-based health facilities, e.g., drug and alcohol services, community MH)? }\end{array}$ & 3 & 2 \\
\hline
\end{tabular}

${ }^{\mathrm{a} C o d}$ 1: (1) COVID-19 general information, (2) MH strategy and (3) MH recommendation

${ }^{\mathrm{b}} \mathrm{Cod}$ 2: (1) MH topics (e.g., symptoms, diseases) and (2) MH-related topics (e.g., physical health) 
disorders, COVID-19 information, $\mathrm{MH}$ strategies and $\mathrm{MH}$ recommendations.

\section{Cluster analysis}

Pearson's chi-squared test was used to determine the variable independence (significance level 0.05). Symmetric and directional measures provided additional information. Independent variables were used to conduct a two-step cluster analysis (all variables were binary). The distance used was log-likelihood, and the grouping method was the Akaike information criterion.

\section{Results}

\section{Study selection}

The search strategy identified 88 documents published as of April 15th, 2020, as the most relevant documents at the beginning of the pandemic. No duplicates were found (Fig. 1). In the eligibility phase, 26 documents fulfilled the inclusion criteria (Fig. 1). There was a strong agreement between CGA and NA (kappa value $=0.787$, $p=0.000 ;$ ICC $=0.881, p=0.000)$.

\section{Study characteristics}

The general population was the target for almost all the documents $(99.06 \%$, Table 2), and the predominant format was a report (73.1\%). The documents with more positive "YES" answers were 1 and 13 (85.19\%); documents 5 and 11 had a lower rate (25.93\%). Documents 1 and 13 were the most complete documents (Table 3 ) and documents 5 and 11 were the most specific.

\section{Results of the cluster analysis}

The cohesion and separation profile was excellent (greater than 0.5). No outlier document was found (Table 4). ANOVA showed significant results.

\section{Mental symptoms (indicator group 1, IG1)}

For IG1 (mental symptoms), almost 100\% of the documents had information about stress and anxiety. Depression and loneliness were also widely covered (76.92 and $69.23 \%$ of the selected documents), and sleeping problems and bereavement were less frequently referenced (53.85 and 34.62\%). Cluster 1 emphasized anxiety and depression; cluster 2 highlighted loneliness, anxiety and stress; cluster 3 added to the previous depression; cluster 4 focused on sleeping problems, stress, bereavement and depression.

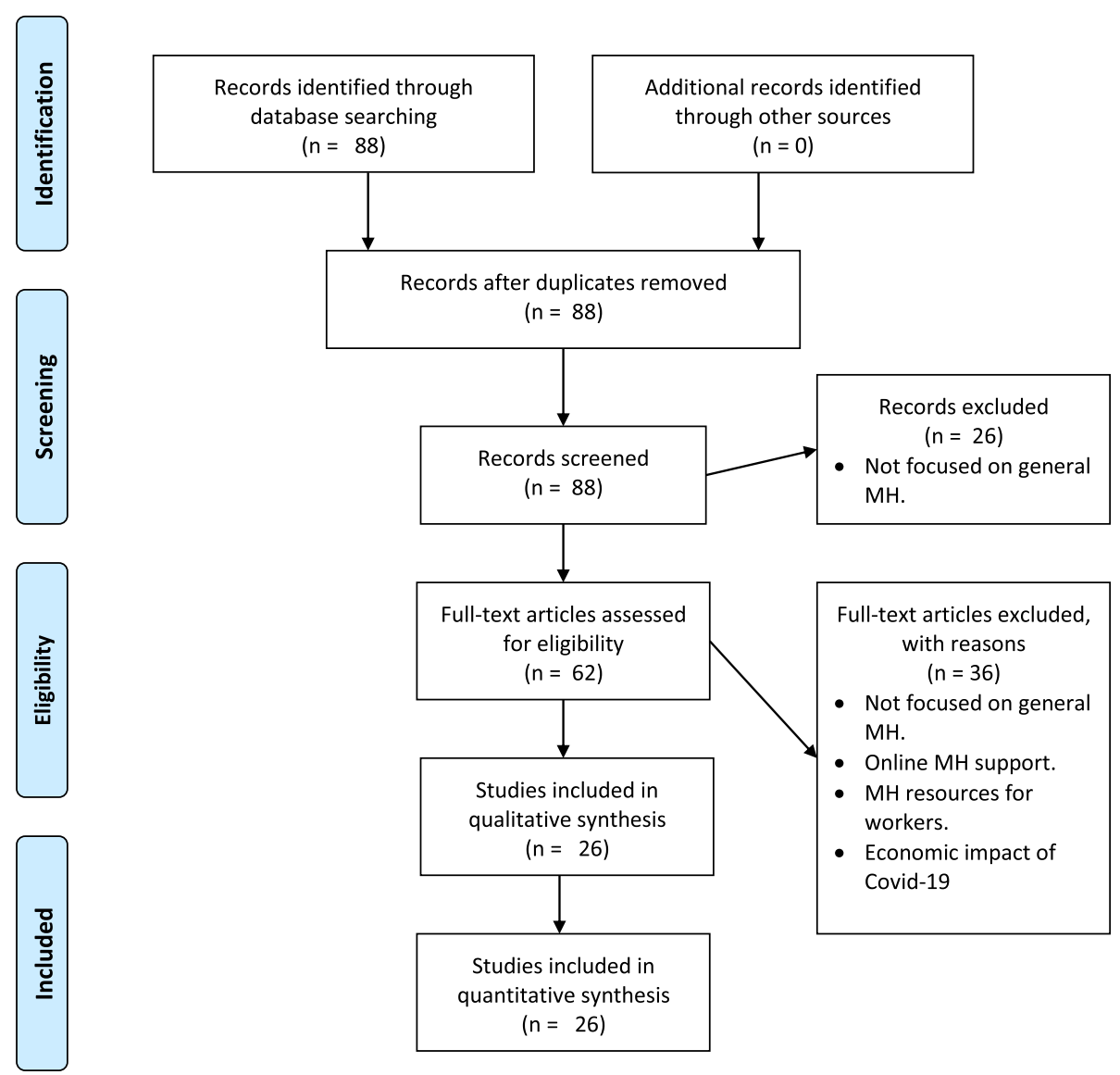

Fig. 1 Flowchart and results. From Moher et al., 2009 [46]. Copyright 2009 by Moher et al. 
Table 2 Documents included in the review

\begin{tabular}{|c|c|c|c|c|}
\hline Code & Authors (year) & Country $^{a}$ & Target population $^{\mathbf{b}}$ & Document type $^{c}$ \\
\hline 1 & Australian Government [50] & 1 & 1 & 2 \\
\hline 2 & Centre for Addiction and Mental Health [51] & 2 & 1 & 2 \\
\hline 3 & Ireland's Health Services [52] & 8 & 1 & 2 \\
\hline 4 & Mental Health Ireland [53] & 8 & 1 & 2 \\
\hline 5 & Gobierno de México [54] & 10 & 1 & 2 \\
\hline 6 & Mental Health America [55] & 16 & 1 & 2 \\
\hline 7 & Centers for Disease Control and Prevention [56] & 16 & 1 & 2 \\
\hline 8 & MindHK [57] & 3 & 1 & 1 \\
\hline 9 & Centre for Health Protection [58] & 3 & 1 & 2 \\
\hline 10 & New Zealand Government [59] & 11 & 1 & 2 \\
\hline 11 & Spanish Society of Psychiatry [60] & 14 & 1 & 1 \\
\hline 12 & Psychology General Council of Spain [61] & 14 & 1 & 2 \\
\hline 13 & Gov.UK (United Kingdom Government) [62] & 4 & 1 & 2 \\
\hline 14 & Mental Health Foundation [63] & 4 & 1 & 2 \\
\hline 15 & Government of Canada [64] & 2 & 1 & 2 \\
\hline 16 & Nidirect Government Services [65] & 8 & 1 & 2 \\
\hline 17 & Santépsy.ch [66] & 6 & 1 & 2 \\
\hline 18 & Confédération suisse [67] & 15 & 1 & 2 \\
\hline 19 & Psychografimata [68] & 7 & 1 & 2 \\
\hline 20 & Official College of Psychology of Catalonia [69] & 14 & 1 & 1 \\
\hline 21 & ॥ post [70] & 9 & 1 & 2 \\
\hline 22 & MIELI ry [71] & 5 & 1 & 2 \\
\hline 23 & Ordem dos psicologos [72] & 13 & 2 & 1 \\
\hline 24 & Beyond Blue [73] & 1 & 1 & 2 \\
\hline 25 & Australian Psychological Society [74] & 1 & 1 & 1 \\
\hline 26 & Mental Health Commission of Canada [75] & 2 & 1 & 2 \\
\hline
\end{tabular}

${ }^{2}$ Countries: (1) Australia, (2) Canada, (3) China: Hong Kong, (4) England, (5) Finland, (6) Germany, Switzerland and France; CORAASP and CLASS, (7) Greece, (8) Ireland, (9) Italy, (10) Mexico, (11) New Zealand, (12) Portugal, (13) Scotland, (14) Spain, (15) Switzerland and (16) United States of America

${ }^{\mathrm{b}}$ Target population: (1) General population and (2) Older adults

'Document type: (1) Report and (2) Web page

\section{Mental disorders (indicator group 2, IG2)}

In IG2 (mental disorders), anxiety was the most highlighted disorder (96.15\%), followed by depression and substance use (73.08 and 69.23\%). The second most common disorders were eating disorders, bipolar and obsessive-compulsive disorders (42.31, 30.77 and 30.77\%, respectively). Finally, somatoform disorders were less relevant (7.69\%). Cluster 1 highlights schizophrenia, anxiety, depression, substance use and eating disorders; and cluster 2 emphasizes anxiety, depression and substance use.

\section{COVID-19 information (indicator group 3, IG3)}

All the questions had a similar weight [80, 90\%] in IG3 (COVID-19 information), and almost all the guides provided relevant information about COVID-19 (79.3\%).

\section{MH strategies \& MH topics (indicator group 4, IG4)}

For IG4 (MH strategies \& MH topics), all the guides include tips for maintaining good $M H$, describe some psychological skills to help people cope with their anxiety and worry about COVID-19, and promote social connection at home. Globally speaking (global layer, Fig. 2), question 26 (information on how to support a loved one who is very anxious about COVID-19) is the most relevant question (65.38\% "YES"). It is followed by questions 28 (including information on how to manage stress in case of positive testing), 29 (how to reduce stigma) and 32 (how to manage stress and anxiety) (38.46\% each). Question 27 (stress management while people are waiting for COVID-19 test results) is less relevant.

In IG4, Cluster 1 highlighted maintaining good $M H(Q 4)$, descriptions of psychological skills to help people with anxiety and worries (Q6) and promotion of social connection at home 
Table 3 Number of positive (YES) answers in percentage (\%) per document and indicator group (IG)

\begin{tabular}{|c|c|c|c|c|c|c|c|c|}
\hline Code & IG1 & IG2 & IG3 & IG4 & IG5 & IG6 & IG7 & Total \\
\hline 1 & 50.00 & 88.89 & 100.00 & 77.78 & 80.00 & 100.00 & 100.00 & 85.19 \\
\hline 2 & 83.33 & 66.67 & 100.00 & 88.89 & 80.00 & 91.67 & 40.00 & 79.63 \\
\hline 3 & 100.00 & 77.78 & 100.00 & 44.44 & 60.00 & 83.33 & 60.00 & 72.22 \\
\hline 4 & 100.00 & 66.67 & 100.00 & 77.78 & 40.00 & 83.33 & 60.00 & 72.22 \\
\hline 5 & 33.33 & 22.22 & 0.00 & 33.33 & 10.00 & 33.33 & 40.00 & 25.93 \\
\hline 6 & 66.67 & 66.67 & 100.00 & 88.89 & 100.00 & 91.67 & 60.00 & 83.33 \\
\hline 7 & 83.33 & 33.33 & 100.00 & 100.00 & 90.00 & 75.00 & 80.00 & 77.78 \\
\hline 8 & 100.00 & 11.11 & 66.67 & 33.33 & 20.00 & 50.00 & 0.00 & 37.04 \\
\hline 9 & 50.00 & 22.22 & 100.00 & 33.33 & 20.00 & 83.33 & 60.00 & 48.15 \\
\hline 10 & 50.00 & 11.11 & 100.00 & 66.67 & 90.00 & 100.00 & 80.00 & 70.37 \\
\hline 11 & 50.00 & 33.33 & 0.00 & 33.33 & 30.00 & 16.67 & 0.00 & 25.93 \\
\hline 12 & 83.33 & 22.22 & 0.00 & 66.67 & 50.00 & 58.33 & 40.00 & 50.00 \\
\hline 13 & 100.00 & 44.44 & 100.00 & 100.00 & 90.00 & 100.00 & 60.00 & 85.19 \\
\hline 14 & 83.33 & 77.78 & 100.00 & 66.67 & 70.00 & 83.33 & 60.00 & 75.93 \\
\hline 15 & 83.33 & 22.22 & 100.00 & 55.56 & 60.00 & 75.00 & 20.00 & 57.41 \\
\hline 16 & 83.33 & 22.22 & 100.00 & 44.44 & 80.00 & 83.33 & 80.00 & 66.67 \\
\hline 17 & 50.00 & 66.67 & 100.00 & 44.44 & 70.00 & 66.67 & 40.00 & 61.11 \\
\hline 18 & 66.67 & 66.67 & 100.00 & 44.44 & 70.00 & 66.67 & 40.00 & 62.96 \\
\hline 19 & 33.33 & 11.11 & 66.67 & 55.56 & 60.00 & 50.00 & 40.00 & 44.44 \\
\hline 20 & 66.67 & 11.11 & 100.00 & 66.67 & 60.00 & 66.67 & 40.00 & 55.56 \\
\hline 21 & 66.67 & 22.22 & 100.00 & 33.33 & 40.00 & 75.00 & 40.00 & 50.00 \\
\hline 22 & 50.00 & 66.67 & 100.00 & 55.56 & 60.00 & 75.00 & 80.00 & 66.67 \\
\hline 23 & 66.67 & 22.22 & 100.00 & 33.33 & 20.00 & 41.67 & 20.00 & 37.04 \\
\hline 24 & 100.00 & 22.22 & 100.00 & 100.00 & 90.00 & 83.33 & 80.00 & 79.63 \\
\hline 25 & 83.33 & 77.78 & 100.00 & 33.33 & 60.00 & 66.67 & 100.00 & 68.52 \\
\hline 26 & 83.33 & 55.56 & 100.00 & 55.56 & 70.00 & 75.00 & 40.00 & 66.67 \\
\hline
\end{tabular}

Note. Bold guides with higher percentages and shadowed guides with lower percentages

(Q8). Cluster 2, in addition to the previous clusters, emphasized Q26 again. Cluster 3 also focused on reducing stigma (Q19) and Q26. Finally, Cluster 4 emphasized Q26, including information on how to manage stress while people wait for results (Q27) and how to manage stress when they have a positive test (Q28) (Fig. 2).
MH strategies \& MH-related topics (indicator group 5, IG5)

IG5 shows a global pattern (global layer, Fig. 2) dominated by including information on how to maintain a healthy lifestyle (Q5) and including information for caregivers (Q35). Less relevant were the inclusion of

Table 4 Cluster analysis results for each indicator group (IG)

\begin{tabular}{|c|c|c|c|c|c|c|}
\hline \multirow[t]{2}{*}{ Indicator group (IG) } & \multicolumn{6}{|c|}{ Number of observations } \\
\hline & Cluster 1 & Cluster 2 & Cluster 3 & Cluster 4 & Cluster 5 & Cluster 6 \\
\hline IG1 Mental symptoms & 7 & 4 & 8 & 7 & & \\
\hline IG2 Mental disorders & 9 & 17 & & & & \\
\hline IG3 COVID-19 information & 23 & 3 & & & & \\
\hline IG4 MH strategies \& MH topics & 8 & 6 & 6 & 6 & & \\
\hline IG5 MH strategies \& MH-related topics & 3 & 6 & 5 & 5 & 4 & 3 \\
\hline IG6 MH recommendations \& MH topics & 6 & 7 & 3 & 10 & & \\
\hline IG7 MH recommendations \& MH-related topics & 4 & 8 & 8 & 3 & 3 & \\
\hline
\end{tabular}




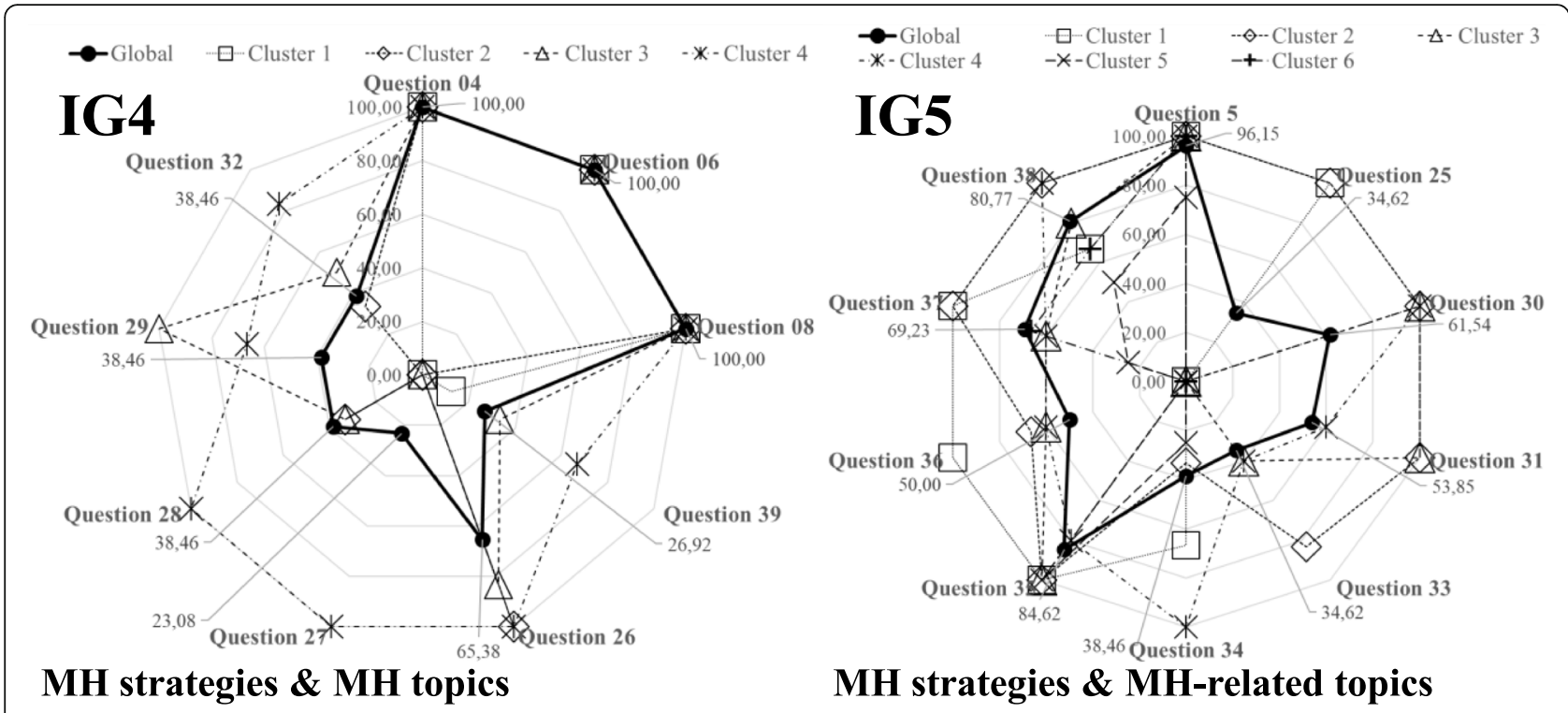

Fig. 2 Percentages of positive (YES) answers for IG4 and IG5

information for healthcare workers (Q30), how to support them (Q31), developing advice on medication access (Q37), and working at home (Q38). Cluster 1 highlighted information on how to maintain a healthy lifestyle (Q5), including special mentions of people with disabilities (Q25), including information for caregivers (Q35), including information on financial support (Q36) and developing advice for medication access (Q37). Cluster 2 focused on Q5 and Q25, including information and support for healthcare workers $(\mathrm{Q} 30)$, including information on how to support health care workers Q31, Q35, and Q37 and working at home (Q38). Cluster 3 highlighted Q5, Q30, Q31 and Q35. Cluster 4 emphasized Q5, Q25, information for people suffering from domestic violence (Q34) and Q38. Clusters 5 and 6 had only one relevant question each, Q5 and Q35, respectively (Fig. 2).

\section{$\mathrm{MH}$ recommendations \& $\mathrm{MH}$ topics (indicator group 6,} IG6)

The global profile of IG6 highlighted all the questions (from 76.92 to 100\%), except: offer an online psychological assessment? (Q11, 23.08\%), provide feedback on the psychological assessment results (Q12, 19.23\%) and provide telephone or online contact with the general practitioner (Q14, 38.46\%). Cluster 1 had the same pattern, but Q14 was less important. For Cluster 2, Q11 and Q12 were not relevant. Cluster 3 highlighted providing emotional support (Q7) and providing a community forum (Q17). Cluster 4 emphasized Q7 and describes how to access $M H$ services (Q9).

\section{MH recommendations \& $\mathrm{MH}$-related topics (indicator} group 7, IG7)

Globally speaking, IG7 highlighted include information for parents $(Q 19,88.46 \%)$, how to explain the coronavirus to children (Q20,76.92\%) and providing alternatives for older adults to be connected (Q22, 61.54\%). Cluster 1 emphasized all the questions except including guidelines for COVID-19 outbreaks in residential care facilities (Q24). In Cluster 2, Q19 was the most relevant. Cluster 3 focused on Q19 and Q22. Cluster 4 was dominated by questions $Q 19, Q 20, Q 22$ and Q24. In Cluster 5, most answers were "NO", except for $Q 22$.

\section{Linked questions in the documents}

Some of the questions were linked in the selected documents, which means that when one question appeared, the other question also appeared (Yes \& Yes answers). In IG1 (mental symptoms), most of the guides linked loneliness and depression (54\% of the documents), anxiety and stress (96\%) and anxiety and sleeping problems (50\%) symptoms, and the former two relationships were very strong. This was not the case for depression and bereavement (27\%). The larger cluster (Cluster 3 ) showed a perfect link between loneliness and depression and anxiety and stress, with the relationship between anxiety and sleeping problems also being strong.

In IG2 (mental disorders), there was a strong link between anxiety and substance use (65\%) and anxiety and depression (69\%), but anxiety and eating disorders and anxiety and obsessive-compulsive disorder had lower relevance (42 and 31\%). Cluster 2 confirmed the previous pattern, but both the anxiety and substance use and anxiety and depression links were less relevant.

In IG3 (COVID-19 information), very few documents (12\%) did not link ... includes information related to the latest information on COVID-19 (Q1) and ... includes 
information on the latest news about the global response to the COVID-19 outbreak (Q3).

In IG4, most of the selected documents did not include information on how to manage stress if they have tested positive (Q28) and include information on stigma and how to reduce it (Q29) (Fig. 3).

The conceptual maps (Fig. 4) show that the relationships between including psychological tips for maintaining good mental health and coping with COVID-19 (Q4), describing some psychological skills to help people cope with anxiety and worry about COVID-19 (Q6) and promoting social connection at home (Q8) were very strong. Progressively, strong links between the previous questions and does the strategy include information on how to support a loved one who is very anxious about COVID-19 (Q26) and Q29 appeared. Finally, the questions do the strategy include information on how to manage stress while people await test results (Q27), does the strategy include information on how to manage stress and anxiety (Q32) and are there any links for older people related to any symptoms or mental disorders (Q29) were less linked.

In IG5, there was a strong link between describing how to maintain a healthy lifestyle. (Q5) and develop advice on medication access during the COVID-19 pandemic (Q37) (A, Fig. 5) and between Q5 and contemplate working at home (Q38) (B). The relationships between include information for healthcare workers (Q30) and include information on how to support health care workers $(Q 31)(C)$ and between $Q 30$ and develop a strategy for identifying healthcare staff needs as a result of the coronavirus pandemic (Q33) (D) were less relevant. Cluster 2 highlighted Yes \& Yes in all the analysed links.

In IG6, most of the documents strongly linked how to access $M H$ services (Q9) and provide $M H$ treatment/ intervention alternatives $(Q 13,84 \%)$ as well as $Q 9$ and provide telephone or online contact with the psychologist (Q15, 81\%). The relationship between providing any phone or online MH services (Q16) and providing an online community forum (Q17) was also important (52\%).

In IG7 and from a global perspective, there was a strong link (77\%) between including information for parents (Q19) and including information on how to explain the coronavirus to children (Q20). However, in clusters 2 and 3, Q19 alone was also relevant. All the documents without Q19 and Q20 were concentrated in cluster 5.

\section{Discussion}

To the best of our knowledge, this is the first study to collect empirical background on the main online international strategies and recommendations developed to cope with the psychological impact of COVID-19 at a very early stage of the pandemic. Considering its negative $\mathrm{MH}$ effects [76, 77], the existence of common patterns is relevant to a) classify documents from a multidimensional perspective (indicator groups), b) help others develop new reports and guides, c) link key subjects appropriately according to the objectives, and d) adapt new documents to local situations in a coordinated way, assuring the dissemination of trusted information.

It was possible to adapt the PRISMA statements to systematically review online international $\mathrm{MH}$ reports and guides. Then, by combining statistical analysis, graphical tools and conceptual maps in document structural analysis, researchers can provide quick and reliable results from online webpages and reports.

The new questionnaire successfully assessed the structure and content of the selected documents. Its structure can be considered the gold standard for reviewing online documents related to $\mathrm{MH}$ strategy and recommendations. The new methodological approach surpasses qualitative approaches by using cluster analysis, graphical tools and conceptual maps. Selected documents were classified by 1) their degree of complexity, 2) their degree of specificity by grouping the variables and 3) the purpose or objectives to be met (strategic, recommendations, $\mathrm{MH}$ topics and $\mathrm{MH}$-related topics).

The common patterns can be studied from a unidimensional or multidimensional perspective. Anxiety and stress symptoms as well as anxiety disorders were included in almost all documents. Comorbid pathologies such as substance use and depression were also frequently incorporated together. Including information about the pandemic characteristics and evolution as well as about the strategies or recommendations designed and implemented to deal with them was also relevant.

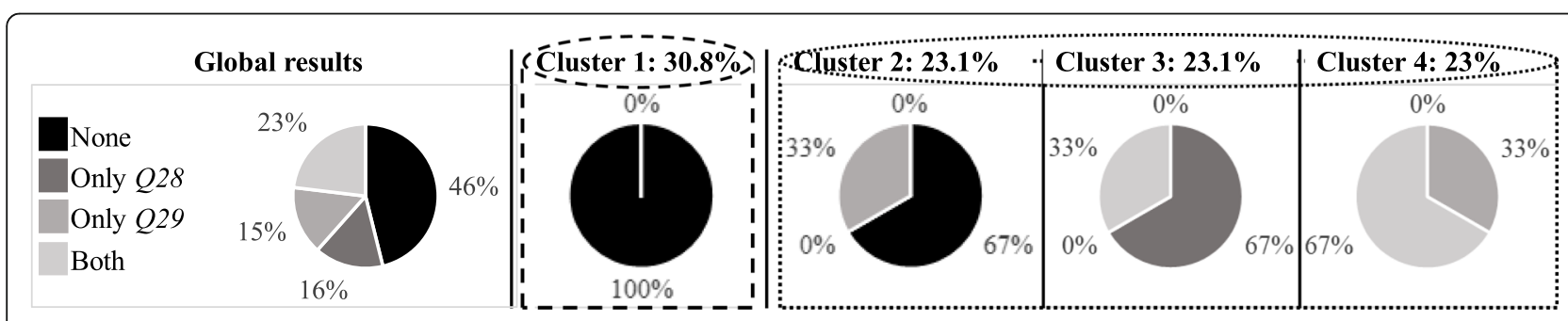

Fig. 3 Q28-Q29 


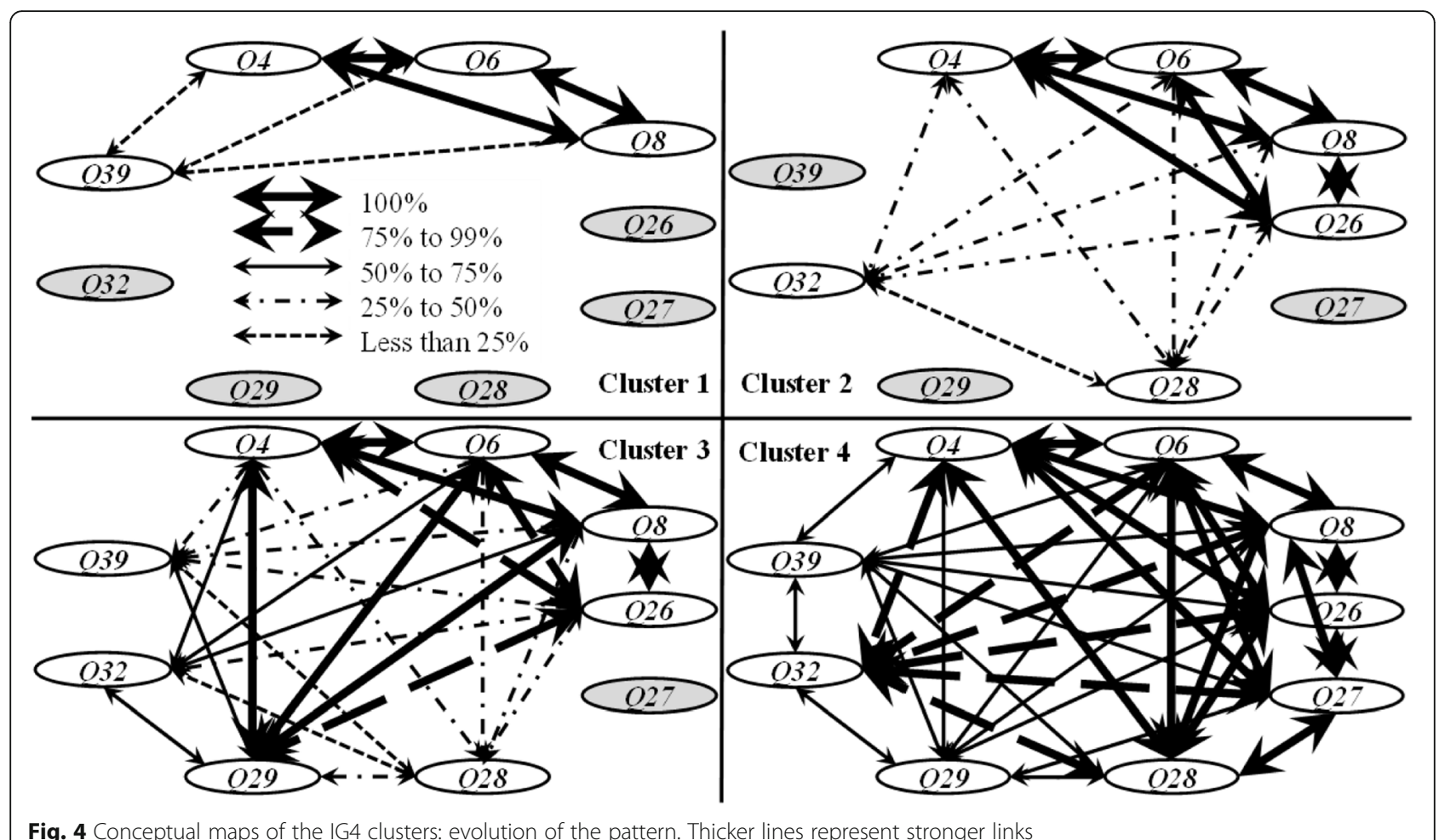

$\mathrm{MH}$ decision makers highlighted the relevance of people being informed by trusted sources because information reduces uncertainty. The selected documents include updated information on international strategies for fighting COVID-19 and how this fight is happening to avoid fear and panic.
All the selected documents emphasize the relevance of available practical tools for managing anxiety and worries about COVID-19 and maintaining social connections to achieve good $\mathrm{MH}$. Most of them also highlight the need to design instruments to help others inside the family. Maintaining a healthy lifestyle and including

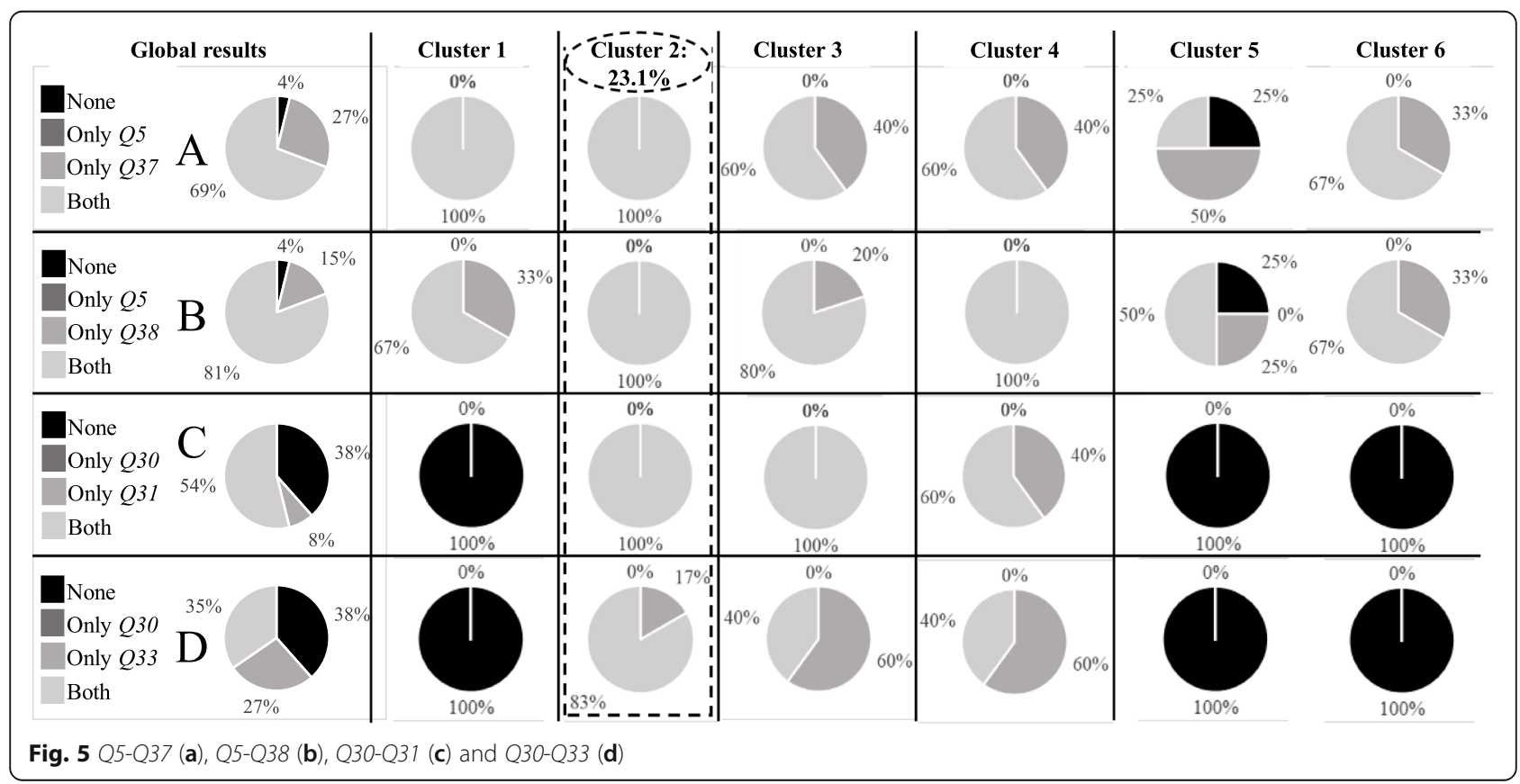


information on how to take care of others are key subjects developed by the documents.

All countries were concerned about the importance of providing real emotional support. Therefore, a strong e$\mathrm{MH}$ system, including coordinated telecommunications and computer-based tools, is required to meet population needs and distinguish $\mathrm{MH}$ users from the general population who need punctual counselling or community support. e-MH allows the screening of pandemic symptoms and mental disorder incidence to prevent new consequences. Knowing how to access $\mathrm{MH}$ care is critical in emergency situations. Finally, many documents developed child-adapted information for parents; however, very few had instruments adapted for older adults.

Most of the documents linked loneliness and depression as well as anxiety and stress symptoms, frequently comorbid. Anxiety and substance use as well as anxiety and depression disorders were also related because during the pandemic, people mainly suffer from anxiety, depression, posttraumatic stress and obsessive-compulsive disorder [78, 79].

Surprisingly, most of the documents did not include specific information on how to manage stress for persons who had tested positive or how to reduce the potential stigma of the infection. It is worth highlighting that the inclusion of stigma was related to the document level of complexity; those that concern the identification and reduction of stigma were the most complex ones and have previously included information on, for example, symptoms such as stress and anxiety.

However, many documents linked healthy lifestyle maintenance to advise on medication access (adherence). Both the information availability on medication access and on how to organize this access were considered essential.

Working from home is suddenly new for some professionals. Selected documents provided tips about the management of indispensable contact with supervisors and colleagues to feel supported. Performing safety and hygiene precautions while considering personal finances were essential in this situation [80]. A lack of information about how to manage this type of work could increase anxiety and stress levels.

There is global consensus on the relevance of appropriate information for healthcare workers. Many selected documents link this fact to practical tools for supporting these professionals. Nevertheless, it was less common to find tips for determining the needs of healthcare staff, such as those developed by the Academy of Medical Royal Colleges [81] and the City Mental Health Alliance UK [82].

In the selected documents, planners frequently linked $\mathrm{MH}$ services access items to online treatment/intervention alternatives. This fact can be critical for screening and control purposes because of face-to-face constraints.

The main limitation of this review is the increasing number of documents that are being developed in response to the pandemic. This review was performed rapidly at the beginning of the lockdown; therefore, it offers a global vision of the very first reactions of $\mathrm{MH}$ planners to address the evolution of the pandemic. Language selection was also a limitation because documents and guidelines were written in the corresponding native languages (Chinese, Korean, etc.) at a very early stage of the pandemic. Only documents published in English, Spanish, French, Italian and Portuguese were included. Finally, selected documents and guidelines were published not only by governments and international organizations but also by mass media, and their reliability is not uniform.

\section{Conclusions}

From a methodological perspective, the PRISMA guidelines can be adapted for carrying out rapid reviews of online documents. This process integrates expert knowledge to adapt the systematic review methodology (search strategy and eligibility criteria) and design questionnaires (key variables and domains) with statistical analysis, graphical tools and conceptual maps to produce useful results for rapid decision making. Cluster analysis identifies independent variables and highlights potential common patterns in the selected indicator groups. Based on these common patterns, conceptual maps show the evolution of document complexity (relationships between variables). Once these critical components (independent variables, common patterns and document complexity) are stated, decision makers can use them to design new context-based strategies and recommendations to support $\mathrm{MH}$ users and their families.

From an $\mathrm{MH}$ care point of view, this study identifies the most important symptoms, diseases, strategies and recommendations that $\mathrm{MH}$ planners selected for designing online documents at a very early stage of the pandemic. In a very complicated and unknown situation, these elements were combined by experts in specific profiles (clusters) from the simplest to the more complex. This finding shows that, from a basic structure, decision makers incorporated new items to improve information coverage. This sequential process is not random but is dominated by stronger links between these elements.

From an MH planning perspective, the results indicate that standard care provision should be progressively adapted to digital care while ensuring acute patient treatments [83]. e-MH is a useful resource in an emergency, but only when staff are specifically trained and receive reliable information to maintain their health and provide better care. To reach these goals, it is necessary to ensure social connections and to reinforce digital infrastructures to reduce gaps, especially in older adult groups $[84,85]$. This global health crisis could be an 
opportunity to reinforce and integrate e-MH in care ecosystems.

It is crucial to develop strategies to avoid the stigmatization of people who have coronavirus, at-risk groups, $\mathrm{MH}$ users and healthcare workers. Only the most sophisticated online documents address this issue.

Most of the selected documents include strategies for dealing with children online, but in contrast, the needs of older adults in online spaces are frequently forgotten. Internet literacy skills training for this collective should be improved by including specific links and tools in online documents.

\section{Abbreviations}

MH: Mental health; WHO: World Health Organization; APA: American Psychological Association; UN: United Nations; ICC: Intraclass Correlation Coefficient; IG: Indicator group

\section{Acknowledgements}

This paper was made possible by the assistance of the International CIty and urban Regional CoLlaborativE (IIMHL-I-CIRCLE) and the PSICOST groups.

\section{Authors' contributions}

NA and CGA designed the study. NA and CGA carried out the systematic review. All authors reviewed the results and contributed to discussions about the final version of the tool for assessing the documents. NA, CGA and LSC drafted the manuscript and all authors contributed to and approved the final version. All authors read and approved the final version of the manuscript.

\section{Authors' information}

Dr. Nerea Almeda (Ph.D.), Assistant Professor of Clinical Psychology at Loyola University. She is a member of PSICOST and the American Psychological Association. She holds a Ph.D. in Data Science. She focuses her research on improving mental health care provision by using decision support systems. She has participated in European and national projects focusing on the evaluation of mental health services and financing systems. She has received several research prizes awarded by the American Psychological Association. Prof. Dr. Carlos R. García-Alonso (Ph.D.), Professor of Operational Research and Quantitative Methods. He holds a Ph.D. in Engineering. He focuses his research on mental health problems and models of simulation related to efficiency. He has supervised researchers in several Spanish-funded projects and participated as a researcher in different European-funded projects. Prof. Dr. Luis Salvador-Carulla (Ph.D.), honorary president and active member of PSICOST. He is the head of the Centre for Mental Health Research at the Research School of Population Health, Australian National University (ANU) in Canberra (Australia). He has been advisor to the Government of Catalonia (Spain), the Spanish Ministry of Health, the European Commission (EC) and the World Health Organization (WHO). His research has been focused on developing decision support systems in health and social policy, including tools for the analysis of technical efficiency and benchmarking, indicators for health policy analysis and priority settings in mental health and disability.

\section{Funding}

Part of this study was funded by the Carlos III Health Institute (PI18/01521) and the Regional Government of Andalusia (PY18-RE-0022). The first funded the hardware and software used for collecting data (the checklist) and carrying out the statistical analysis (cluster and conceptual maps). The Regional Government of Andalusia contributed by financing a research assistant who participated in cleaning the databases (data management and graphic design). The funding body did not participate in the design of the study and collection, analysis, and interpretation of data and in writing the manuscript. The funding agreements ensured the authors' independence.

\section{Availability of data and materials}

All data supporting our findings will be shared on request. The documents included in the systematic review are available in the references.

\section{Ethics approval and consent to participate}

This study does not contain any studies with human participants or animals performed by any of the authors.

\section{Consent for publication}

Not applicable.

\section{Competing interests}

The authors declare that they have no competing interests.

\section{Author details}

${ }^{1}$ Department of Psychology, Universidad Loyola Andalucía, Seville, Spain. ²Department of Quantitative Methods, Universidad Loyola Andalucía, Seville, Spain. ${ }^{3}$ Centre for Mental Health Research, Research School of Population Health, ANU College of Health and Medicine, Australian National University, Canberra, Australia.

Received: 3 June 2020 Accepted: 14 December 2020

Published online: 15 January 2021

\section{References}

1. Deng C-X. The global battle against SARS-CoV-2 and COVID-19. Int J Biol Sci. 2020;16:1676-7. https://doi.org/10.7150/ijbs.45587.

2. Yi Y, Lagniton PNP, Ye S, Li E, Xu R-H. COVID-19: what has been learned and to be learned about the novel coronavirus disease. Int J Biol Sci. 2020;16: 1753-66. https://doi.org/10.7150/ijbs.45134.

3. World Health Organization. Rolling updates on coronavirus disease (COVID19). 2020. https://www.who.int/emergencies/diseases/novel-coronavirus-201 9/events-as-they-happen.

4. Worldometer. COVID-19 CORONAVIRUS PANDEMIC. 2020. https://www. worldometers.info/coronavirus/.

5. Centers for Disease Control and Prevention. Coronavirus (COVID-19). 2020. https://www.cdc.gov/coronavirus/2019-nCoV/index.html.

6. Fiorillo A, Gorwood P. The consequences of the COVID-19 pandemic on mental health and implications for clinical practice. Eur Psychiatry. 2020;63: e32. https://doi.org/10.1192/j.eurpsy.2020.35.

7. Ho CS, Chee CY, Ho RC. Mental health strategies to combat the psychological impact of COVID-19 beyond paranoia and panic. Ann Acad Med Singap. 2020;49:155-60.

8. Montemurro N. The emotional impact of COVID-19: From medical staff to common people. Brain Behav Immun. 2020.

9. Cullen W, Gulati G, Kelly BD. Mental health in the Covid-19 pandemic. QJM. 2020.

10. Calati R, Ferrari C, Brittner M, Oasi O, Olié E, Carvalho AF, et al. Suicidal thoughts and behaviors and social isolation: a narrative review of the literature. J Affect Disord. 2019;245:653-67.

11. Lima CKT, de Carvalho PMM, de Lima IAAS, de Nunes JVAO, Saraiva JS, de Souza Rl, et al. The emotional impact of coronavirus 2019-nCoV (new coronavirus disease). Psychiatry Res. 2020;287:112915.

12. Yao H, Chen J-H, Xu Y-F. Patients with mental health disorders in the COVID-19 epidemic. Lancet Psychiatry. 2020;7:e21.

13. Wang C, Pan R, Wan X, Tan Y, Xu L, Ho CS, et al. Immediate psychological responses and associated factors during the initial stage of the 2019 Coronavirus Disease (COVID-19) epidemic among the general population in China. Int J Environ Res Public Health. 2020:17.

14. Li S, Wang Y, Xue J, Zhao N, Zhu T. The impact of COVID-19 epidemic declaration on psychological consequences: a study on active Weibo users. Int J Environ Res Public Health. 2020;17.

15. Liu N, Zhang F, Wei C, Jia Y, Shang Z, Sun L, et al. Prevalence and predictors of PTSS during COVID-19 outbreak in China hardest-hit areas: gender differences matter. Psychiatry Res. 2020;287:112921.

16. Bo H-X, Li W, Yang Y, Wang Y, Zhang Q, Cheung T, et al. Posttraumatic stress symptoms and attitude toward crisis mental health services among clinically stable patients with COVID-19 in China. Psychol Med. 2020:1-7.

17. Xiang Y-T, Yang Y, Li W, Zhang L, Zhang Q, Cheung T, et al. Timely mental health care for the 2019 novel coronavirus outbreak is urgently needed. Lancet Psychiatry. 2020;7:228-9.

18. Zhai Y, Du X. Mental health care for international Chinese students affected by the COVID-19 outbreak. Lancet Psychiatry. 2020;7:e22.

19. Sani G, Janiri D, Di Nicola M, Janiri L, Ferretti S, Chieffo D. Mental health during and after the COVID-19 emergency in Italy. Psychiatry Clin Neurosci. 2020. 
20. Lai J, Ma S, Wang Y, Cai Z, Hu J, Wei N, et al. Factors associated with mental Health outcomes among health care workers exposed to coronavirus disease 2019. JAMA Netw Open. 2020;3:e203976.

21. Huang J, Liu F, Teng Z, Chen J, Zhao J, Wang X, et al. Care for the psychological status of frontline medical staff fighting against COVID-19. Clin Infect Dis. 2020

22. Greenberg N, Docherty M, Gnanapragasam S, Wessely S. Managing mental health challenges faced by healthcare workers during covid-19 pandemic. BMJ. 2020;368:m1211.

23. Kang L, Ma S, Chen M, Yang J, Wang Y, Li R, et al. Impact on mental health and perceptions of psychological care among medical and nursing staff in Wuhan during the 2019 novel coronavirus disease outbreak: a cross-sectional study. Brain Behav Immun. 2020; https://doi.org/10.1016/j.bbi.2020.03.028.

24. Thornicroft G, Tansella M. The balanced care model: the case for both hospitaland community-based mental healthcare. Br J Psychiatry. 2013;202:246-8.

25. Li L. Challenges and priorities in responding to COVID-19 in inpatient psychiatry. Psychiatr Serv. 2020;71:624-6. https://doi.org/10.1176/appi.ps. 202000166.

26. Pinals DA, Hepburn B, Parks J, Stephenson AH. The behavioral health system and its response to COVID-19: a snapshot perspective. Psychiatr Serv. 2020; 71:1070-4. https://doi.org/10.1176/appi.ps.202000264.

27. Starace F, Ferrara M. COVID-19 disease emergency operational instructions for mental Health departments issued by the Italian society of epidemiological psychiatry. Epidemiol Psychiatr Sci. 2020;29:e116.

28. Australian Government. Fact sheet. Coronavirus (Covid-19). 2020. https:// www.health.gov.au/sites/default/files/documents/2020/03/covid-19-nationalhealth-plan-supporting-the-mental-health-of-australians-through-thecoronavirus-pandemic.pdf.

29. Australian Government. Looking after your mental health during coronavirus (COVID-19) restrictions. 2020. https://www.health.gov.au/news/ health-alerts/novel-coronavirus-2019-ncov-health-alert/ongoing-supportduring-coronavirus-covid-19/looking-after-your-mental-health-duringcoronavirus-covid-19-restrictions.

30. Centre for Addiction and Mental Health. Mental Health in Canada: Covid-19 and Beyond CAMH Policy Advice. 2020. http://www.camh.ca/-/media/files/ pdfs---public-policy-submissions/covid-and-mh-policy-paper-pdf.pdf.

31. Bojdani E, Rajagopalan A, Chen A, Gearin P, Olcott W, Shankar V, et al. COVID-19 pandemic: impact on psychiatric care in the United States. Psychiatry Res. 2020;289:113069 https://doi.org/10.1016/j.psychres.2020. 113069.

32. Royal College of Nursing. COVID-19 guidance on mental health care delivery. 2020. https://www.rcn.org.uk/clinical-topics/mental-health/covid-1 9-guidance-on-mental-healthcare-delivery.

33. Royal College of Nursing. Guidance for inpatient mental health staff. 2020. https://www.rcn.org.uk/clinical-topics/mental-health/covid-19-guidance-onmental-healthcare-delivery.

34. National Association of Psychiatric Intensive Care \& Low Secure Units. Managing acute disturbance in the context of COVID-19. 2020. https://napicu. org.uk/wp-content/uploads/2020/03/COVID-19_guidance_appendix.pdf.

35. Royal College of Psychiatrists. COVID-19: Community mental health settings. 2020. https://www.rcpsych.ac.uk/about-us/responding-to-covid-19/ responding-to-covid-19-guidance-for-clinicians/community-and-inpatientservices/covid-19-working-in-community-mental-health-settings.

36. Wind TR, Rijkeboer M, Andersson G, Riper H. The COVID-19 pandemic: the "black swan" for mental health care and a turning point for e-health. Internet Interv. 2020;20:100317. https://doi.org/10.1016/j.invent.2020.100317.

37. Torous J, Jän Myrick K, Rauseo-Ricupero N, Firth J. Digital mental health and COVID-19: using technology today to accelerate the curve on access and quality tomorrow. JMIR Ment Heal. 2020;7:e18848. https://doi.org/10.2196/18848.

38. Yao H, Chen J-H, Xu Y-F. Rethinking online mental health services in China during the COVID-19 epidemic. Asian J Psychiatr. 2020;50:102015.

39. Liu S, Yang L, Zhang C, Xiang Y-T, Liu Z, Hu S, et al. Online mental health services in China during the COVID-19 outbreak. Lancet Psychiatry. 2020;7: e17-8. https://doi.org/10.1016/S2215-0366(20)30077-8.

40. Yang Y, Li W, Zhang Q, Zhang L, Cheung T, Xiang Y-T. Mental health services for older adults in China during the COVID-19 outbreak. Lancet Psychiatry. 2020;7:e19.

41. Moreno C, Wykes T, Galderisi S, Nordentoft M, Crossley N, Jones N, et al. How mental health care should change as a consequence of the COVID-19 pandemic. Lancet Psychiatry. 2020;7:813-24 https://doi.org/10.1016/S22150366(20)30307-2
42. Kestel D. WHO's contribution to the MHPSS response to COVID-19: an overview. Geneva; 2020. https://rsph.anu.edu.au/files/WHO Contribution to COVID Response.pdf.

43. American Psychological Association. APA COVID-19 Information and Resources. 2020. https://www.apa.org/topics/covid-19/.

44. United Nations. Wellbeing tips for UN Personnel. 2020. https://www.un.org/ en/coronavirus/wellness.

45. Druss BG. Addressing the COVID-19 pandemic in populations with serious mental illness. JAMA Psychiatry. 2020.

46. Moher D, Liberati A, Tetzlaff J, Altman DG, Group TP. Preferred reporting items for systematic reviews and meta-analyses: the PRISMA statement. PLoS Med. 2009;6:e1000097.

47. Almeda N, García-Alonso CR, Salinas-Pérez JA, Gutiérrez-Colosía MR, Salvador-Carulla L. Causal modelling for supporting planning and management of mental health services and systems: a systematic review. Int J Environ Res Public Health. 2019;16:1-27. https://doi.org/10.3390/ ijerph16030332.

48. García-Alonso CR, Almeda N, Salinas-Pérez JA, Gutiérrez-Colosía MR, SalvadorCarulla L. Relative technical efficiency assessment of mental health services: a systematic review. Adm Policy Ment Heal Ment Heal Serv Res. 2019.

49. Romero-López-Alberca C, Gutiérrez-Colosía MR, Salinas-Pérez JA, Almeda N, Furst M, Johnson S, et al. Standardised description of health and social care: a systematic review of use of the ESMS/DESDE (European Service Mapping Schedule/Description and Evaluation of Services and DirectoriEs). Eur Psychiatry. 2019;61:97-110.

50. Australian Government. Head to health COVID-19 support. 2020. https:// headtohealth.gov.au/Covid-19-support/Covid-19\%0D\%0A.

51. Centre for Addiction and Mental Health. Mental health and the COVID-19 pandemic. 2020. https://www.camh.ca/en/health-info/mental-health-andcovid-19.

52. Ireland's Health Services. Your mental health. Advice on how to mind your mental health during the coronavirus outbreak. 2020. https://www2.hse.ie/ mental-health/.

53. Mental Health Ireland. Minding our mental health during COVID-19. 2020. https://www.mentalhealthireland.ie/get-support/covid19/.

54. Gobierno de México. Salud mental. 2020. https:/coronavirus.gob.mx/salud-mental/.

55. Mental Health America. Mental health and COVID-19-information and resources. 2020. https://mhanational.org/covid19.

56. Centers for Disease Control and Prevention. Coronavirus disease 2019 (COVID-19). 2020. https://www.cdc.gov/coronavirus/2019-ncov/daily-lifecoping/managing-stress-anxiety.html?CDC_AA_refVal=https\%3A\%2F\%2 Fwww.cdc.gov\%2Fcoronavirus\%2F2019-ncov\%2Fprepare\%2Fmanagingstress-anxiety.html.

57. MindHK. Managing our mental health \& staying well during a virus outbreak. Responding to 2019-nCOV. 2020. https://www.mind.org.hk/wpcontent/uploads/2020/02/ResponseCoronavirusENG6.2.2020-.pdf.

58. Centre for Health Protection. Mental health infostation. 2020. https://www. chp.gov.hk/mhi/index_en.html.

59. New Zealand Government. Ways we're uniting agains COVID-19. 2020. https://covid19.govt.nz/.

60. Spanish Society of Psychiatry. CUIDE SU SALUD MENTAL DURANTE LA CUARENTENA POR CORONAVIRUS. 2020. http://www.sepsiq.org/file/ InformacionSM/SEPCOVID19-SaludMentalCuarentena.pdf\%0D\%0A.

61. Psychology General Council of Spain. Orientaciones para la gestión psicológica de la cuarentena por el Coronavirus. 2020. http://www.infocop. es/view_article.asp?id=8655.

62. GOV.UK. Guidance for the public on the mental health and wellbeing aspects of coronavirus (COVID-19). 2020. https://www.gov.uk/government/ publications/covid-19-guidance-for-the-public-on-mental-health-andwellbeing/guidance-for-the-public-on-the-mental-health-and-wellbeingaspects-of-coronavirus-covid-19.

63. Mental Health Foundation. How to look after your mental health during the Coronavirus outbreak. 2020. https://www.mentalhealth.org.uk/coronavirus.

64. Government of Canada. Taking care of your mental health during COVID-19. 2020. https://www.canada.ca/en/public-health/services/publications/ diseases-conditions/taking-care-mental-health.html.

65. Nidirect Government Services. Coronavirus (COVID-19): taking care of your mental health and wellbeing. 2020. https://www.nidirect.gov.uk/articles/ coronavirus-Covid-19-taking-care-your-mental-health-and-wellbeing.

66. Santépsy.ch. SANTÉ MENTALE \& COVID-19. 2020. https://www.santepsy.ch/ fr/pages/sante-mentale-Covid-19/sante-mentale-Covid-19-910. 
67. Confédération suisse. Nouveau coronavirus: Recommandations pour la vie quotidienne. 2020. https://www.bag.admin.ch/bag/fr/home/krankheiten/ ausbrueche-epidemien-pandemien/aktuelle-ausbrueche-epidemien/novelcov/empfehlungen-fuer-den-alltag.html.

68. Psychografimata. Corona: 8 ways to take care of your mental health. 2020. https://

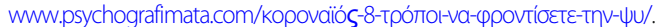

69. Official College of Psychology of Catalonia. Recomendaciones de gestión psicológica durante cuarentenas por enfermedades infecciosas. 2020. https://www.copc.cat/adjuntos/adjunto_15214/v/Guia de gestión psicológica frente a cuarentenas por enfermedades infecciosas-Español. pdf?tm=1584361.

70. $\quad$ II Post. Come restare mentalmente sani durante la quarantena. 2020. https:// www.ilpost.it/2020/03/16/consigli-psicologici-coronavirus/.

71. MIELY ry. Koronaviruksen ai-heuttama huolta voi lievittää. 2020. https://mieli. fi/fi/koronaviruksen-aiheuttamaa-huolta-voi-lievittää.

72. Ordem dos Psicologos. COVID-19 COMO LIDAR COM UMA SITUAÇÃO DE ISOLAMENTO SE FOR UM CIDADÃO SÉNIOR (OU SEU FAMILIAR). 2020 https://www.ordemdospsicologos.pt/ficheiros/documentos/covid_19_ seniores.pdf.

73. Beyond Blue. Coronavirus mental wellbeing support service. 2020. https:// coronavirus.beyondblue.org.au/.

74. Australian Psychological Society. Coronavirus (COVID-19) information for Australians. 2020. https://www.psychology.org.au/COVID-19-Australians.

75. Mental Health Comission of Canada. Resource Hub: Mental health and wellness during the COVID-19 pandemic. 2020. https://www. mentalhealthcommission.ca/English/covid19.

76. Brooks SK, Webster RK, Smith LE, Woodland L, Wessely S, Greenberg N, et al. The psychological impact of quarantine and how to reduce it: rapid review of the evidence. Lancet (London, England). 2020;395:912-20.

77. Galea S, Merchant RM, Lurie N. The mental health consequences of COVID19 and physical distancing: the need for prevention and early intervention. JAMA Intern Med. 2020. https://doi.org/10.1001/jamainternmed.2020.1562.

78. Fineberg NA, Van Ameringen M, Drummond L, Hollander E, Stein DJ, Geller $D$, et al. How to manage obsessive-compulsive disorder (OCD) under COVID-19: A clinician's guide from the International College of Obsessive Compulsive Spectrum Disorders (ICOCS) and the Obsessive-Compulsive Research Network (OCRN) of the European College of Neurops. Compr Psychiatry. 2020:152174. https://doi.org/10.1016/j.comppsych.2020.152174.

79. Horesh D, Brown AD. Traumatic stress in the age of COVID-19: a call to close critical gaps and adapt to new realities. Psychol Trauma. 2020;12:331-5.

80. Mental Health and Productiviy Pilot. Thrive at tome. Homeworkers toolkit. 2020. https://mhpp.me/thrive-at-home/homeworkers/.

81. Academy of Medical Royal Colleges. COVID-19 - Mental health \& wellbeing for healthcare professionals. 2020. https://www.aomrc.org.uk/covid-19mentalwellbeing/.

82. City Mental Health Alliance UK. Supporting the mental health of furloughed workers during the coronavirus outbreak. 2020. http://citymha.org.uk/wpcontent/uploads/2020/04/Furloughed-workers-FINAL.pdf.

83. National Health Service England. Managing capacity and demand within inpatient and community mental health, learning disabilities and autism services for all ages. 2020. https://www.england.nhs.uk/coronavirus/wpcontent/uploads/sites/52/2020/03/Managing-demand-and-capacity-acrossMH-LDA-services_25-March-final-1.pdf.

84. Australian Government. Supporting the mental health of Australians through the coronavirus pandemic. 2020. https://www.health.gov.au/sites/ default/files/documents/2020/03/covid-19-national-health-plan-supporting the-mental-health-of-australians-through-the-coronavirus-pandemic.pdf.

85. Scottish Government. New mental health support. 2020. https://www.gov. scot/news/new-mental-health-support/.

\section{Publisher's Note}

Springer Nature remains neutral with regard to jurisdictional claims in published maps and institutional affiliations.

Ready to submit your research? Choose BMC and benefit from:

- fast, convenient online submission

- thorough peer review by experienced researchers in your field

- rapid publication on acceptance

- support for research data, including large and complex data types

- gold Open Access which fosters wider collaboration and increased citations

- maximum visibility for your research: over $100 \mathrm{M}$ website views per year

At BMC, research is always in progress.

Learn more biomedcentral.com/submissions 